\title{
Entrevista
}

\section{CONVERSA COM A EDUCADORA MATEMÁTICA BEATRIZ D'AMBROSIO: UMA CONSTRUTIVISTA RADICAL}

Por: Gabriela Félix Brião

Em 2013, quando a professora Beatriz D'Ambrosio realizou um semestre sabático, visitando a UNESP/Rio Claro e ministrou um curso intitulado "Clássicos da Pesquisa na Educação Matemática Norte Americana", eu estava presente em suas aulas assistindo como aluna ouvinte. Nesse momento conheci um pouco melhor a Bia - como gosta de ser chamada -, e suas ideias me fizeram perceber que estava no caminho certo quanto a minha escolha em fazer um doutorado em Educação Matemática. Foi então que a convidei para fazer uma entrevista para publicar na e-Mosaicos, pois queria que suas ideias fossem divulgadas na UERJ, uma das maiores universidades brasileiras e reconhecida por sua formação de professores, que se utiliza do CAp-UERJ como campo de estágio, pesquisa e extensão. Ela prontamente aceitou, mas por conta da falta de tempo, só conseguimos tocar esse projeto durante o XIV CIAEM (Congresso Interamericano de Educação Matemática), ocorrido no início de maio de 2015 na cidade de Tuxtla Gutierrez no México.

A professora Beatriz já trabalha nos Estados Unidos há mais de vinte anos. Hoje é professora titular do departamento de Matemática da Miami University, na cidade de Oxford, em Ohio. É reconhecida por seus trabalhos em Educação Matemática, focados principalmente na formação do professor-pesquisador da matemática viável de seu aluno.

Atualmente, a professora Beatriz, em conjunto com a profa. Dra. Celi Espasandin Lopes, está introduzindo um conceito novo na área de formação de professores no Brasil, a insubordinação criativa. Este tema está sendo discutido em uma série de livros organizados pelas duas professoras e que já conta com três volumes publicados pela Mercado de Letras.

A entrevista foi realizada a várias mãos pela linha de Matemática Lúdica do grupo de pesquisa GEMat-UERJ. Cada integrante do grupo teve a sua participação, seja na confecção das perguntas, na transcrição da entrevista ou na correção do texto. Gostaria de agradecer especialmente a Daniela Mendes Vieira da Silva, Flávia Streva Nunes, Shirlei Barros, Bruno Gonçalo Penedo Souza, Darling Domingos Arquieres e Carolina Azevedo França do Nascimento, por suas contribuições.

GABRIELA: Profa. Beatriz D'Ambrosio, você é uma educadora matemática que teve parte de sua formação nos Estados Unidos e já trabalha nesse país como professora formadora há mais de vinte anos. Fale um pouco sobre a sua formação como educadora matemática e se há grandes diferenças na Educação Matemática das crianças americanas e das brasileiras? 
BEATRIZ:Vou falar um pouco da minha formação e depois falarei um pouco do que eu noto dasdiferenças. Minha formação, como educadora matemática, começou com o curso de matemática na Unicamp. Logo dei aula numa escola para crianças que tinham dificuldades de aprendizagem, e era uma escola que oferecia acompanhamento das crianças, além da escola. Nessa escola, os pais procuravam esse serviço de acompanhamento, para que a gente tentasse recuperar crianças que estavam indo mal na escola. E aí eu comecei a me interessar muito pelos motivos pelos quais as crianças iam mal na escola e achei que eu poderia ajudar muito mais se eu tivesse mais formação. Então eu fui atrás de fazer um mestrado na época, uma pós-graduação, e não existia no Brasil, a Educação Matemática.

\section{GABRIELA: Isso foi em 82, não, você se formou em 82 no mestrado.}

BEATRIZ: No mestrado sim, mas foi em 80 que eu saí, para fazer mais um pouco de formação, me especializar em problemas de aprendizagem. Na minha cabeça era isso que eu ia fazer. Aí eu cheguei aos Estados Unidos, escolhi um programa e comecei a fazer essa formação de pós-graduação e conhecer a área de Educação Matemática que aqui no Brasil ainda não se constituía como uma área de formação [não era ainda] não existia o curso de pós-graduação, não existiam revistas. Era o comecinho no Brasil, nos Estados Unidos já estava bem estabelecido. Então eu fui com a intenção de fazer mestrado e acabei ficando e fazendo o doutorado mesmo de vez, direto e conhecendo o mundo da pesquisa da Educação Matemática. E aí eu voltei para o Brasil, isso em 87, e comecei a trabalhar por um semestre na PUC de São Paulo. Criamos um curso. A PUC de São Paulo estava interessada em abrir um curso de pós-graduação. Então criamos cursos e teve muito aluno interessado em fazer trabalho de pesquisa, trabalho de pesquisa-ação, tinha vários que já davam aula. A PUC se caracterizava por essa questão de alunos da licenciatura que já davam aula. Entãose interessaram porque eu voltei com essa noção de pesquisa-ação, do professor-pesquisador e os alunos lá se interessaram muito. A gente teve um grupo de pesquisa que começou,estava interessado em estudar aprendizagem das crianças sobre fração, foi muito legal lá. Aí em seguida, fui para Unicamp, comecei a dar aula na Unicamp, na licenciatura e fui do grupo que abriu a licenciatura noturna na Unicamp, que foi o primeiro curso noturno da Unicamp. Foi muito interessante porque atendia a aluno diferente, grupo de alunos, que trabalhavam durante o dia e procuravam fazer licenciatura à noite, com muita vontade, muito esforço, querendo muito. E o meu trabalho então era sempre com resolução de problemas, problemas investigativos. Eu percebia que para os alunos era muito estranho. Eles não sabiam bem como se comportar diante da gente fazendo problemas,eu não ensinava nada, falava:"então vamos fazer um problema e ver o que que a gente sabe", resistiam muito no começo, eles queriam saber mas o que que é isso? O que é que eu anoto? Comprei caderno para quê? E eu falava: Ah você jogou tudo fora (quando apagavam o "rascunho"), tudo que é importante você acabou de jogar no lixo. Ah mas é rascunho? Não rascunho, pois é você fazendo matemática. Foi um trabalho de tentar mudar a cabeça deles mesmo. Quanto ao que é uma aula de matemática, porque eles eram da licenciatura. A minha formação foi essa, ter a oportunidade de ver muita coisa diferente, de imaginar outras possibilidades, e o meu programa de pós-graduação teve muito isso. O meu orientador e o grupo lá onde eu fiz o doutorado eram muito focados na resolução de problemas e a questão dos problemas investigativos era muito nova, problemas abertos, investigativos, de fazer essa linguagem, problemas que são sobre fazer matemática e a ideia de ensinar matemática através de problemas ainda era muito nova. Então, como é que é o resto da pergunta mesmo? 
GABRIELA: Se você vê grandes diferenças na educação matemática das crianças americanas, e das crianças brasileiras, se existe algo que te chame mais atenção em relação às diferenças.

BEATRIZ: Olha, só posso falar das diferenças, pelo que eu vivi com a minha filha, porque eu estou muito afastada da sala de aula do Brasil, né? Mas, recentemente quando eu fui para Brasil (no primeiro semestre de 2013), que a minha filha fez o Ensino Médio, o primeiro ano do Ensino Médio, eu percebi, ela percebeu, ela que me contava, que ela sentia necessidade de trabalhar com problemas, com situações para entender e ela falava muito claro, nossa eles falam, falam, falam e eu não tenho oportunidade de pensar por mim, eu tenho que seguir o que eles falam, as regras eu não tenho a oportunidade, eu gostaria de criar alguma coisa, alguma regra que eu vou lembrar mais. Ela falava, eu sempre lembro e entendo mais se fui eu que criei, então, fez muita falta para ela isso. Eu não vou generalizar que, na escola não se faz isso, no Brasil. Mas, na escola que ela estudou, para ela fez muita falta uma metodologia que envolvesse mais o aluno, onde o centro do trabalho fosse o aluno e não o professor fazendo tudo e o aluno copiando.

GABRIELA: Certa vez você me disse que era uma construtivista radical. Você ainda se aproxima dessa forma de pensar o ensino da Matemática? Você poderia falar um pouco sobre que características um professor de matemática deve ter para que se caracterize como um construtivista radical?

BEATRIZ:Bom, se eu me ainda me caracterizo como construtivista radical? Eu diria que sim porque construtivismo radical é a maneira como eu entendo como as pessoas vão aprender a matemática, quais os processos cognitivos que elas vão viver para aprender matemática.A ideia do construtivismo radical é que as pessoas vão confrontar uma situação problema que elas não saibam o que fazer, não saibam nem como começar.O professor construtivista estuda os alunos, tudo que o aluno faz ou que, estudando, observando, tentando entender para poder colocar situações que sabem que os estudantes tem o que eles precisam para resolver, quer dizer, eu não vou pôr uma coisa frustrante, eu tenho que ter segurança que o estudante tem o que ele necessita para resolver. Muitas vezes o que que ele precisa para resolver é, talvez, reorganizar as ideias um pouco, para poder resolver aquele problema mas eu, como professora construtivista, tenho que ter segurança que ele tem o que é necessário, os conceitos necessários, talvez não tenha o procedimento ainda, não imaginou um procedimento, mas as partes essenciais estão já concretizadas, e aí a construção vem dele se deparar com uma situação problema, uma situação investigativa desconhecida, que eu não falei como fazer que ele não tem ideia como fazer e que ele vai buscar ideias, ele tem que ser criativo ele tem que ser um aluno que valoriza a criatividade, e com isso ele vai conseguir. Eu acredito muito em grupos, porque aí um estimula o outro, porque um conceito que está mais aparente para um aluno,que ele contribui para o entendimento, os outros contemplam aquilo, debatem, discutem e avançam juntos. Muita gente critica 0 construtivismo radical, dizendo que é um trabalho independente e individualista, e não é. A construção do conhecimento se dá colaborativamente mas ele é individual, ele se dá para cada aluno de uma forma diferente. Não tem essa história de conhecimento compartilhado.Para cada um, a compreensão é singular, porque as estruturas individuais são diferentes, as experiências anteriores são diferentes. Então, para cada um, ele pode trabalhar em conjunto, ele pode trabalhar colaborativo, colaborar com colegas, e vão construir um produto final colaborativo, mas a construção da ideia do conhecimento eo 
e-Mosaicos - Revista Multidisciplinar de Ensino, Pesquisa, Extensão e Cultura do Instituto de Aplicação Fernando Rodrigues da Silveira (CAp-UERJ)

V. 4 - N. 7 - JUNHO 2015 - ISSN: 2316-9303

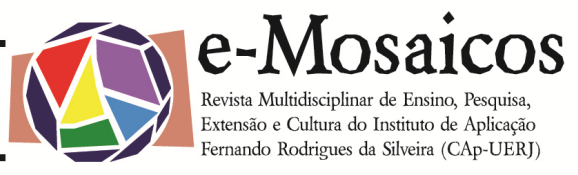

entender daquela matemática é um processo individual que ocorre para cada um de uma forma diferenciada. Acho que tem muita gente que entende mal o que é o construtivismo e principalmente o radical, porque a gente está falando dos processos cognitivos da cabeça de uma pessoa.

GABRIELA: Como um professor se caracterizaria como construtivista radical, e o que ele precisa ter? Tem algo que salte aos olhos?

BEATRIZ: Eu acho que para mim a coisa principal que diferencia o professor construtivista radical dos outros é que ele ouve o aluno de forma a dar valor ao que o aluno está falando, e quem determina a agenda da aula, e quem determina o que vai acontecer na aula não é o professor, é o aluno. O professor segue o aluno, e não o aluno segue o professor. 0 professor, segue, coloca, a direção pro aluno, baseado naquilo que o aluno está fazendo, é diferente de você entrar com um plano de aula pré-estabelecido, claro você leva um plano de aula, mas você tem que estar disposto a reformular o plano na hora, baseado no que o aluno faz.

GABRIELA: No texto $O$ Ensino Construtivista temos que o Professor Construtivista é aquele que estuda a construção matemática de seus alunos e que interage com os alunos num espaço de aprendizagem cujo desenho está baseado, pelo menos em parte, num modelo de Matemática do aluno e no texto $O$ ProfessorPesquisador diante da produção escrita dos seus alunos vemos que é necessário que esse perfil pesquisador se faça numa análise hermenêutica onde o professor "ouve acreditando" e assim encoraja seus alunos a compartilharem suas estratégias e pensamentos onde todos podem aprender uma nova construção do pensamento matemático, inclusive o professor. Esse conjunto de atividades e postura Construtivista e Reflexiva do Professor demandam novas estruturas escolares de planejamento, avaliação, currículo, espaço físico e número de alunos por turma ou é possível de ser realizada dentro dos moldes de uma Escola Tradicional brasileira? Que caminhos o docente da Educação Básica pode percorrer a fim de vencer as barreiras impostas não só pela estrutura escolar mas pela pressão cultural do Ensino que se baseia e se concentra em resultados de Exames como o ENEM?

BEATRIZ: Então aí entramos em contradição né? A gente tem um sistema de ensino que valoriza o conhecimento pré-fabricado, que é o conhecimento único para todos, como se isso fosse possível.Temos um sistema de ensino baseado numa falta de pensar em como as pessoas aprendem, uma coisa única para todos vai de encontro à construção do conhecimento, a entender 0 ensino como aprendizagem de forma construtivista. Independente da maneira que a gente trabalha, se a gente está ciente que os alunos estão construindo conhecimento e o professor busca criar esses modelos, ou seja, quando o professor faz uma pergunta, ele não faz a pergunta para determinar se o aluno sabe ou não sabe, se está certo ou errado, ele faz a pergunta porque ele está curioso se o aluno já fez essa ligação, já fez essa construção, já fez essa conexão. Não adianta ele dizer não, tá errado, ele tem que pensar:"poxa nesse momento, o aluno acha isso, então ele tem que trabalhar com isso aqui, então eu vou ter que trabalhar com isso", então é muito, se a gente acredita de fato na construção do conhecimento, agente vai trabalhar sempre essa construção do conhecimento.Quando contamos alguma coisa para o aluno ou mostramos 
como faz, a gente faz isso muitas vezes, mas tem que estar consciente que ele não está aprendendo. Se alguma coisa acontecer é mímica, é reprodução, mas será que houve mesmo uma construção, uma nova ideia para o aluno, uma coisa que vai ficar com ele, um descobrimento mesmo dele? Então, acho que mesmo dentro do sistema mais tradicional é possível trabalhar construção. Você faz a opção. Eu tenho a opção de contar para o aluno o que ele tem que saber, mas estou consciente que isso não leva à aprendizagem, ou eu tenho a opção de investigar com os alunos novas ideias, sabendo que aquelas coisas que a gente trabalhar, quando houver de fato a construção - quando tem a oportunidade do aluno construir uma ideia-, aquilo fica. Aí eu posso dizer: ele se apropriou da ideia. A ideia surgiu dele, a solução surgiu do aluno e a satisfação de que surgiu, que foi ele que conseguiu resolver o problema, e não simplesmente imitar o outro. Essa satisfação é muito importante para que aquela ideia fique com o estudante. Então, nesse ensino não cabe treinar muita coisa, mil exercícios iguais. É uma perda de tempo. Mil exercícios iguais só cabem quando a metodologia de ensino é uma de reprodução. Quando você tem uma postura de construção do conhecimento, cada problema é novo. Então você fica uma aula, duas, em um problema. Mas um problema rico, cheio de matemática a ser trabalhada, explorada, investigada, questionada, muitas dúvidas...

GABRIELA: Então, a gente está nas escolas brasileiras em geral, e, principalmente no Ensino Médio, concentrando os esforços para que as crianças passem no ENEM, ou para que os professores ganhem algum aumento salarial, porque isso está vinculado às crianças fazerem testes e irem bem nesses testes. Está havendo cada vez mais, - sei que nos EUA também está assim-, essa preocupação do professor não pela aprendizagem, mas que as crianças consigam ir bem nos testes. É nesse sentido que as meninas (do GEMat-UERJ) fizeram essa questão... Que caminho o docente da Educação Básica pode percorrer para vencer essas barreiras impostas por essa pressão de que os alunos façam bem esses testes? O que nos leva à próxima pergunta.

\section{GABRIELA: 0 professor construtivista materializa a própria prática ao proporcionar que o seu aluno reflita o fazer matemático e acabe por se desestabilizar; pois esse será o momento de novas resoluções, novas maneiras de encontrar as respostas. $\mathrm{Na}$ atualidade, temos muitos professores construtivistas com essa prática de levar o seu aluno a elaborar novos saberes matemáticos, invalidando a máxima de que a matemática é de difícil compreensão?}

BEATRIZ: Eu acho que a gente tem hoje mais do que tinha. Eu acho que a gente vai continuar sempre avançando. Os cursos de formação de professores têm essa visão do novo professor que abala mais essa perspectiva. Nas séries iniciais, tem muito, tem muito mais, mas conforme o aluno vai indo para o Ensino Médio, os professores ficam mais tímidos para fazerem aquilo que eles acham que de fato seria melhor para o aluno. Professor novo, principalmente, ele se intimida diante do ENEM, diante dos exames. Eles acham que de fato, mostrando para o aluno tudo o que ele poderia encontrar em um exame, o aluno vai estar mais bem preparado. Enquanto que o aluno melhor preparado é capaz de resolver um problema que ele nunca viu antes. Esse é o aluno que está bem preparado: o aluno que é capaz de resolver não somente as coisas que ele lembra, mas resolver coisas que ele nunca viu. Então é uma grande ilusão o professor achar que ele consegue dar para o aluno exemplos de tudo quanto é tipo de problema que ele possa encontrar em um exame. E daí achar que ele vai lembrar a solução de todos os tipos de problema que ele pudesse encontrar no exame. É uma ilusão isso. Ninguém tem memória a esse ponto de conseguir 
lembrar tudo. Então qual é o bom aluno que vai se sair bem no ENEM? Aquele ativo, que não se intimida quando lê o problema e pensa "ai meu Deus do céu, nunca vi esse". Ele não se intimida, ele lê o problema, ele busca, vou tentar isso, vou tentar aquilo, acho que isso está certo, acho que isso vai dar certo... é o aluno que vai se sair melhor no exame desses que avalia grande quantidade de conhecimento que a gente não consegue acumular. Então a gente trabalha menos conteúdo, mas a gente trabalha o conteúdo de forma que o aluno se sinta autônomo no seu pensar, que ele sinta que ele pode resolver coisas que ele nunca viu. Ele tem estratégias, ele é criativo, tem muitas fórmulas que a gente faz os alunos decorarem que são besteira. $\mathrm{O}$ aluno que entende o conteúdo não precisa decorar as fórmulas. Análise combinatória, por exemplo, cada fórmula boba da gente ficar fazendo o aluno decorar, porque todos aqueles problemas podem ser resolvidos intuitivamente... tem muita fórmula, fórmula de área, tem muita coisa que é bobagem.

GABRIELA: Até que ponto o repertório de histórias pessoais dos alunos, assim como suas produções escritas, deve ser levado em consideração no processo de comunicação entre professor e aluno, no ensino dito construtivista?

BEATRIZ: No construtivismo as histórias do aluno são tudo. E a gente não conhece a história de todos os alunos, então parte do trabalho do professor é criar oportunidades do aluno compartilhar os saberes que ele traz para a sua aula. Essa é outra ilusão que a gente tem. Que o aluno sabe só aquilo que a gente ensina. $O$ aluno vem cheio de conhecimento e a gente nunca tem a sensibilidade, o cuidado de acessar esse conhecimento. E fazer 0 modelo do conhecimento do aluno é isso. Eu falo para os meu alunos, muitas vezes, as primeiras duas ou três semanas de aula, não é conteúdo novo, é oportunidade de a gente aprender quem é o aluno, o que ele traz, quais são as coisas, os conhecimentos, que ele sabe bem, que ele usa, que isso vai ser ponto de partida para coisas novas. O ponto de partida para coisas novas é o que o aluno sabe bem, não é porque é o primeiro capítulo do livro do ano que faz sentido começar ali, pode ser que eu não possa começar ali, pode ser que eu tenha que começar em outro ponto, ou pode ser que começar ali seja fácil demais, que eu tenha que começar de um ponto mais adiantado, mais avançado. Então, conhecer a história do aluno é o trabalho mais importante do professor. $\mathrm{E}$ as dúvidas que a gente tem, a gente começa a explorar a história de vida, explorar as dificuldades, as lacunas que possam existir por falta de oportunidade... por isso que o professor construtivista tem que ser um professor-pesquisador. Ele tem que estar a todo momento buscando o que o aluno traz, que vai poder ser material para usar, mas aí claro a escrita do aluno é uma oportunidade da gente acessar o pensamento de vários alunos ao mesmo tempo e aí nós professores estudamos essas escritas.

\section{GABRIELA: 0 professor construtivista consegue se surpreender ao levar em consideração a potencial zona de construção dos seus alunos, considerando a matemática do aluno como legítima?}

BEATRIZ: Eu acho que se surpreende o tempo inteiro. A partir do momento em que você pega a resposta do aluno e você trabalha dentro de uma perspectiva, que você diz, o aluno acredita que está certo. Então eu tenho que entender o porquê. O que esse aluno está entendendo? Muitas vezes a resposta que a gente pode, num primeiro momento, considerar errada do aluno, na verdade o que está acontecendo é que ele está respondendo outra pergunta. Mas esse aluno não percebeu o que fez. A pergunta não era a nossa intenção. 
Quando você começa a analisar o trabalho dele, você percebe aaaah! Ele está respondendo a pergunta tal, que foi como ele interpretou a pergunta. Ou era mais interessante, ou os elementos do problema apontavam mais para essa direção. Parecia mais importante para ele saber aquilo, responder aquilo. Então acho que quando a gente está aberta a acreditar na solução do aluno, aí toda resposta é uma surpresa. A gente aprende e pensa: como que ele pensou para chegar aí? Aí a gente está aprendendo muita coisa. Nossa! A partir dessa questão foi possível chegar aí... num caminho que eu não imaginava possível. Então você aprende, vai explorando as outras possibilidades que você não imaginou. E é sempre uma surpresa.

GABRIELA: Com a herança da Educação Bancária, que Freire denuncia, as situações onde as ações verbais e não-verbais dos professores e dos alunos não são ouvidas e muito menos interpretadas se tornaram, infelizmente, comuns no cenário do cotidiano escolar brasileiro. Com isso, pouco do que ocorre em sala pode ser considerado ação comum, como bem definiu D'Ambrosio, ou seja, comunicação. Dialogando com as linhas de Psicologia de Piaget e Vygotsky, a pouca interação social e ausência de desequilíbrios produzem ambientes pobres e apáticos para a aprendizagem. Que estratégias iniciais um docente pode tomar para romper com a resistência e os costumes de alunos que já estão habituados a essa rotina escolar muda e depositária de conhecimento?

BEATRIZ: Ih! Essa que é difícil, né? É um trabalho árduo e constante, leva tempo. Criar um ambiente de sala de aula muito diferente do que ele está acostumado. Estabelecer normas de trabalho, deixar claras as expectativas, que quem trabalha na sala de aula é o aluno, que a sala de aula é um ambiente de trabalho, de pesquisa, de investigação, de levantar dúvidas, de discussão... e para o aluno isso é chocante. Muitas vezes ele não está acostumado. Mas essa é uma das coisas que a minha filha sentia falta quando eu falei antes o que eu conheço na educação brasileira das crianças. Ela me dizia: "Mãe! Na minha aula a gente não fala, só quem fala é o professor. Como é que a gente pode aprender se a gente não fala?" Ela dizia isso sempre para mim. "Como que as pessoas aprendem sem falar? Sem testar as ideias? Sem tentar explicar para alguém para ver se está certa a explicação. Não é? Como que pode aprender sem falar?". Então a sala de aula que vai promover esse tipo de aprendizagem, é uma sala muito cheia de energia. As crianças falando o tempo todo, trabalhando, perguntando uma paraa outra, o professor não é a fonte de resposta das perguntas. Elas são. Então eles trabalham juntos nessa perspectiva. É uma comunidade, tem de criar uma comunidade com regras diferentes, mas é interessante que eles gostam. É muito mais cômodo depois que supera o estranhamento inicial, eles adoram. É uma sala que as perguntas deles dão direção à próxima conversa. $O$ poder na sala de aula não está na mão do professor.

GABRIELA: A postura hermenêutica de um professor construtivista sobre as soluções apresentadas dos alunos cria não só o respeito pelo caminho, como encoraja os alunos a pensarem em diversos caminhos de pensamento fora dos tradicionais. Rompe com a cultura da resolução glorificada no acerto para a valorização do caminho como potencial para aprendizagem. Contudo, quais sugestões e estratégias o Professor da Educação Básica pode criar em termos de avaliação que tenham coerência com essa postura e que ao mesmo passo ao final 
de cada etapa escolar (bimestre, trimestre, semestre...) produza uma nota que represente o desenvolvimento daquele aluno?

BEATRIZ: Avaliação é uma contradição com a aprendizagem. A criança aprende o tempo todo, a vida toda. Mas só na escola que ela é avaliada. É uma contradição total. Então eu acho que a avaliação tem de ser criada numa forma, com muita opção, para os alunos mostrarem que eles sabem.Tem um exemplo de uma professora que fez um trabalho muito bonito... ela fala para os alunos: na lição de casa hoje, você vai escrever a prova que você vai fazer amanhã. Vai escrever a prova, o gabarito, e amanhã você vai fazer a prova e a prova que vai valer a nota. Mas eu quero que você escreva uma prova que você tenha certeza de que você consegue tirar dez. Está aqui...o número de questões... eu quero tanto de questões e está aqui o conteúdo. Aí os alunos escrevem a prova que eles têm certeza que eles conseguem tirar dez. Muito interessante, muito interessante!Porque daí você avalia aquilo que ele tem segurança. Você fica muito mais atento àquilo que marcou, que ficou com o aluno. Agora é claro que tem alunos e alunos, mas tem alunos que arriscam mais, que fazem questões absurdamente difíceis, que a gente não sabe resolver às vezes, mas eles preparam o gabarito tudo certinho. $\mathrm{E}$ tem aluno tímido, que tem medo e aí você quer ver através do tempo como eles se arranjam, que eles se arrisquem a algo mais, e aí vem a conversa, onde o professor vira para o aluno e fala que muito bem! A prova esclarece o que ele aprendeu, o que ele entende, mas que, observando, você notou que ele poderia ter posto uma questão mais difícil e você propõe vamos pôr mais essa, vocês juntos constroem uma questão colaborativa entre professor e aluno da própria avaliação. A própria avaliação mostra que o aluno tem voz, tem poder, tem oportunidade de se sair bem, de mostrar o que ele sabe, de brilhar.

GABRIELA: Essa nunca tinha ouvido falar. Mas a avaliação é a parte mais difícil do trabalho.

BEATRIZ: Mas para ser coerente o aluno precisa ter voz. Às vezes os alunos escrevem questões para a prova, formulam questões com clareza, às vezes de forma não muito clara, mas você reformula com eles, vamos melhorar as perguntas, vocês entenderam, questões colaborativas, questões assim para colocar numa prova é muito rico.

GABRIELA: Isso é polêmico dentro da escola que a gente tem.

BEATRIZ: Estamos falando das possibilidades futuras, de um professor arrojado, afim de fazer um trabalho diferente, que pode gerar frutos.

GABRIELA: Vamos nos voltar agora mais para a formação de professores de Matemática.

GABRIELA: Que mudanças necessárias os Cursos de Formação de Professores no Brasil, seja em nível de Graduação ou de Pós-Graduação, precisam ter, de tal maneira a garantir a formação de um Professor-Pesquisador participante na vida matemática de seus alunos? 
BEATRIZ: Eu acho o mais importante na mudança na formação é o tempo de formação com a criança em sala de aula. O que gera maior aprendizagem para o futuro professor é passar muito tempo em sala de aula tentando conversar com as crianças e criar modelos do conhecimento das crianças, propondo questões para as crianças, ouvindo as soluções, trabalhando junto, observando as crianças trabalhando juntas em pares, em grupos pequenos, as conversas delas. Eu acho que a gente faz muito trabalho acadêmico, muita coisa boa de leitura, mas enquanto a leitura não é posta em prática com crianças de verdade é difícil a aprendizagem, por que a aprendizagem vem da ação, da ação e da reflexão. Em sala de aula e na universidade tem pouca ação, se faz pouca ação, quer dizer, você faz problemas matemáticos, mas a ação pedagógica mesmo, de levar uma proposta de trabalho para uma criança, uma ou outra, não precisa ser uma sala inteira, o aluno em formação ele não está preparado para assumir uma sala, uma turma, mas um pequeno grupo sim. Trabalhar com as crianças, conversar com as crianças, dialogar, aprender o que é uma explicação que uma criança entende, versus uma explicação que ficou completamente incompreensível, que pode ser perfeita para um adulto, mas que para a criança não tem o menor sentido. Explorar a história da criança é muito importante. Você cobra do futuro professor, durante os quatro anos de formação,que tivesse pelo menos uma hora por semana em sala de aula com uma criança. Nem precisa ser em sala de aula, pode ser no final de semana, um bingo de matemática, um clube de jogos, uma oportunidade, um tutor, como professor particular, isso tudo é muito válido com uma postura de entender, de aprender sobre as crianças e não: sei tudo e vou te ensinar. Diferente, né?!?!?

GABRIELA: É... muito diferente. De certa forma queremos colonizar as cabeças das crianças.

BEATRIZ: É! Não é possível.

\section{GABRIELA: Há uma resistência e preconceito entre Professores de Matemática que se concentram unicamente no aprofundamento do conteúdo matemático e aqueles que se ocupam de investigar e problematizar as próprias práticas pedagógicas. Em sua opinião, quais poderiam ser as raízes dessas barreiras que se constroem e como vencê-las?}

BEATRIZ: Acho que as barreiras e os preconceitos dos professores que se concentram no conteúdo vêm das experiências de vida escolar desses professores. Eles viveram toda vida escolar aprendendo o que eles sempre chamaram de matemática. De ano para ano, as aulas e a metodologia de trabalho dos seus professores eram idênticas. Nunca tiveram uma experiência investigativa, nunca sentiram a força da construção do conhecimento por conta própria, nunca sentiram a alegria de vencer e resolver um problema que em princípio parecia difícil demais. É natural que sem essas experiências seja difícil imaginar outras possibilidades. Um aspecto importante do processo de formação do professor, que crie um ambiente de investigação, é ele próprio ter a experiência de fazer matemática, de participar de uma comunidade de investigação, de colaborar com colegas na investigação matemática. Sem vivenciar esse processo fica difícil acreditar nas possibilidades dessa metodologia de ensino. 


\section{GABRIELA: Mas tem preconceito? Você sente esse preconceito? Muito forte? De repente nos EUA não tem esse preconceito.}

BEATRIZ: Não encontro muito preconceito. A comunidade matemática não vê o trabalho da Educação Matemática como uma pesquisa, muitas vezes. Mas a comunidade matemática também participa menos e menos da sala de aula e do trabalho de sala de aula, mas isso porque a gente tem a formação de professores, que é bem dividida entre aulas de matemática e as aulas de formação. O educador matemático é quem dá metodologia de ensino, didática, supervisão de estágio, isso tudo é o educador matemático que faz. $\mathrm{Na}$ nossa instituição ainda tem uma vantagem, que vários cursos do futuro professor são dados por educadores matemáticos, apesar de ser do departamento de matemática, mas isso é raro.

GABRIELA: Mas então vocês têm educadores matemáticos o suficiente para suprir essa demanda, pelo menos da parte da educação matemática, da área pedagógica. No Brasil a gente não tem isso. Dentro dos departamentos de matemática tem um ou outro educador matemático, são poucos e às vezes tem matemáticos que se interessam pela Educação Matemática e vão se engajando na área, mas o que a gente vê, pelo menos na UERJ, é a valorizaçãodo conhecimento matemático em detrimento de outras formas de matemática que não formam a "matemática dos matemáticos".

BEATRIZ: É. Outra forma de conhecer e também para o professor de Ensino Médio, por exemplo, a matemática aplicada é muito rica, eles têm poucos cursos de matemática aplicada, modelagem, essas coisas, isso ajuda muito a ver outras possibilidades porque no curso de modelagem, por exemplo, os alunos vão fazer projeto, mesmo em nível superior, ele quer trabalhar com as crianças, com os jovens, então é um exemplo para eles, mas tem às vezes, existem bons professores de matemática pura. Existem metodologias de ensino da matemática superior. Isso é uma coisa que se estuda muito aqui nos Estados Unidos agora, que são as metodologias de ensino na matemática superior, onde o método Moore (método criado por Robert Lee Moore), por exemplo, um método de descoberta, colocando situações e, a partir de situações, os alunos geram o que eles acham que sejam teoremas, conjecturas ou consegue provar ou não, o que é uma prova formal ou não, conta como prova, tudo isso entra em discussão Então é uma forma muito interessante de trabalhar com alunos de ensino superior,não só o futuro professor, mas o futuro matemático também, às vezes é mais cedo do que o doutorado ou mestrado, aí que ele gosta de fato da investigação matemática, porque o curso superior ele não sabe, ele não faz matemática até terminar o curso, só no mestrado é que ele vai fazer, ter uma oportunidade de investigar alguma coisa e levantar uma conjectura, uma hipótese, será que. Você participou da seção do Arthur Powell ontem?

GABRIELA: Não, infelizmente.

BEATRIZ: Eles tinham colocado para aluno umacoisa de geometria euclidiana, então a transferência usando GeoGebra, transferir um segmento de um lugar para o outro e usando toda a construção. Agora vamos falar de construção e eles colocam, pedem para o aluno construir, a partir de um segmento, um triângulo equilátero, etc. e tal, aí um dos alunos traz o diálogo do grupo, um deles fala assim: mas será que tem que ser triângulo equilátero? 
Porque que tem que ser equilátero? E o outro fala: boa pergunta, não sei, será que tem que ser equilátero? Isso no curso superior, aí eles começam a explorar os não equiláteros e chegam à conclusão que não precisava ser equilátero, podia ser isósceles, né? Naquela construção bastava ser um triângulo isósceles. Os alunos descobriram que, com o triângulo equilátero, eles resolviam a questão, mas poderiam ter resolvido com o triângulo isósceles. Essa conclusão dos alunos veio da exploração de uma pergunta levantada por eles próprios... "será que tem que ser um triângulo equilátero?"A partir dessa questão, se desencadeou toda uma investigação matemática ligada à construção proposta.A curiosidade deles levou a todo um novo encaminhamento. É raro acontecer isso num curso superior, mas tem que acontecer mais, assim o aluno, cedo na formação matemática, percebe o que é fazer matemática, que é um conceito complicado: o que é fazer matemática? Tem gente que só descobre isso no mestrado ou no doutorado.

GABRIELA: Mas se, pela perspectiva do aluno, do estudante que está lá na sala do ensino fundamental e médio, é o construtivismo radical, ele consegue alcançar a autoestima desse estudante, ele consegue fazer com que esse estudante perceba que ele também pode fazer o que os outros fazem normalmente, que é matemática. Enfim, eu acho que o construtivismo tem um pouco a ver, ele lida um pouco com a autoestima da criança.

BEATRIZ: É porque principalmente o professor que sabe valorizar (conversa externa), eu acho que tem tudo aver com autoestima da criança, principalmente o professor hermenêutico, o professor que escuta de forma hermenêutica, que é escutar o aluno acreditando que você pode aprender alguma coisa, aí a autoestima do aluno é valorizada. Eu fiz um trabalho semana passada numa sala de aula com crianças e quando a criança falava coisas que me intrigavam, eu escrevia, eu tinha um caderninho e escrevia aí chegou ao ponto que no final da aula alguns alunos chegaram para mim, você escreveu sobre mim hoje? Escreveu aquilo que eu falei? Não foi interessante? Você escreveu? Então eles perceberam o meu interesse na fala deles, o que você está escrevendo? Euestou escrevendo o que você acabou de falar. Por quê? Porque é importante, eu vou estudar e entender melhor o que você falou, aí eles se acham o máximo, que a minha palavra, o que eu falei vai para o livro da professora, vai para o diário da professora.

GABRIELA: Então foi esse o caminho que conseguiu, digamos, para melhorar ou pelo menos diminuir o fracasso escolar numa sala de aula, onde o estudante é estimulado e é ouvido. Essa autoestima dele é levantada, e eu acho que o fracasso escolar não existe num ambiente assim.

BEATRIZ: Não existe, ninguém fracassa, todo mundo participa e fica animado e contribui numa comunidade onde é valorizada a voz do aluno. Eles gostam de participar e se mostrar. Quando eles descobrem, eles querem contribuir, mas eu pensei diferente, eu fiz diferente aí a coisa pega fogo eles são muito entusiasmados, e muda o entusiasmo, porque a aula de matemática é uma aula chata, maçante, mas quando ele está ativo...

GABRIELA: Mas o professor tem que ter uma formação muito boa, formação matemática também. 
BEATRIZ: É. Para poder lidar com isso tudo, mas também pode aprender junto com os alunos, tem coisa que você fica na dúvida e aí vocês vão investigar juntos, estudar juntos.

GABRIELA: Então essa sala de aula permanece um ambiente investigativo mesmo, onde todos estão tentando aprender algo...

BEATRIZ: É. Todo mundo, inclusive o professor, é um membro da comunidade querendo aprender.

GABRIELA: Mas num ambiente assim, já é predeterminado que os estudantes têm que estar em grupos para que eles possam conversar, do que em fileiras separadas.

BEATRIZ: Tem que ser em grupo. Tem professor que pede para trocar as carteiras por mesa, tem muito isso agora nos Estados Unidos, o professor tem a opção de ter carteiras que podem ficar em fila, com mesa para quatro ou seis, mas quatro é melhor, seis fica meio, alguns lideram os outros,ficam... quatro é o melhor. Então tem professor que já entra na escola e já pergunta se já tem essa opção, eu quero mesa, porque ele quer diariamente, constantemente essa troca, que aquelas carteiras de braço não são boas para grupos, não dá certo, a troca, o passar o papel de um para o outro, tudo isso faz parte. Para olhar o que se está fazendo em cada mesa é mais apropriado, mais cômodo, o entusiasmo, que é possível criar esse ambiente os jovens em formação não acreditam, não vê, tem que ver o entusiasmo das crianças.

GABRIELA: E aí o CAP-UERJ, eu acho que é um lugar ideal para formação, mas você me disse que nos Estados Unidos fecharam essas escolas porque elas são muito caras.

BEATRIZ: As laboratoriais?

\section{GABRIELA: É.}

BEATRIZ: E também porque mais e mais, as escolas, tem muitas escolas que tem esses ambientes, nem todas as escolas, mas, nem todas as salas dentro da escola, mas você encontra mais oportunidades de situar o aluno-mestre em formação, numa escola em que o professor se comporta dessa maneira. Então, o que havia de especial, as escolas de laboratório, o custo é muito alto e ela se torna, chegou a se difundir em outras escolas e perdeu um pouco aquela característica, tem pouquíssimo. Acho que não tem nenhuma mais. 